\title{
Foreign body punctured the spleen: An incidental diagnosis
}

\author{
Gizem İnal-Aslan, İbrahim Ötgün, Lütfi Hakan Güney, Akgün Hiçsönmez \\ Department of Pediatric Surgery, Baskent University Faculty of Medicine, Ankara, Turkey \\ E-mail: gizmoluk@hotmail.com \\ Received: 12th July 2016, Revised: 22nd July 2016, Accepted: 24th August 2016
}

\begin{abstract}
SUMMARY: İnal-Aslan G, Ötgün İ, Güney LH, Hiçsönmez A. Foreign body punctured the spleen: An incidental diagnosis. Turk J Pediatr 2017; 59: 97-99.

A foreign body can enter the body via penetration through the skin. In the presented case, a broken syringe needle was found and removed from the splenic parenchyma. In order to prevent such iatrogenic injuries, which could have fatal consequences, the hospital staff must give particular care in the handling of sharp FBs.
\end{abstract}

Key words: foreign body, spleen, penetration, infant.

Foreign body (FB) aspiration and ingestion are not uncommon in children, and sharp FBs can also enter the body by penetration. As these latter cases are rare, the diagnosis can be challenging without a history of penetration ${ }^{1}$, 2. Herein, we present an infant with a sharp FB that punctured the spleen after penetration through the skin of the subscapular area ${ }^{1,2}$.

\section{Case Report}

A six-month-old male was admitted to the hospital with the complaint of constipation. He had no other complaints or symptoms. His physical examination was normal. The X-ray showed a FB (needle) located in the left upper quadrant of the abdomen. As it was assumed that the FB (needle) was located in the stomach (Fig. 1), an upper gastrointestinal endoscopy (UGE) was performed, but it showed no evidence of FB in the stomach. Computerized tomography (CT) was then performed and revealed that the FB (needle) was localized in the splenic parenchyma (Fig. 2). His physical examination was repeated, and a lesion thought to be the entrance site of the needle was found on the left subscapular area. The psychosocial status of the family was not relevant with regard to possible child abuse by the parents or other psychological disorders. After informing the family, an exploratory laparotomy was done, and a $21 \mathrm{G}$ syringe needle, which had been broken for blood sampling, was found in the splenic parenchyma. The sharp end of the needle faced anteriorly, and was located laterally and superficially in the spleen. It was removed with a forceps. There was no active bleeding. The postoperative follow-up was uneventful, and the patient was discharged on the second postoperative day.

\section{Discussion}

A foreign body (FB) can enter the body by ingestion, aspiration or penetration ${ }^{1-5}$. Although FB ingestion is common, FB aspiration is more fatal $^{3}$. Injuries were found to be most common in the first decade of life and tended to affect more males than females. In abdominal FB, ingestion is usually suspected, and it can also lead to extraluminal migration, which can be to solid organs like the spleen and liver ${ }^{6}$.

In the English literature review of FBs in solid organs by Feng et al. ${ }^{7}$, there were 11 cases of FB in the liver ( 9 via extraluminal migration, 2 transcutaneously). Most of the patients had no clear history of entrance. Similarly, FB in the spleen was also reported via ingestion or penetration ${ }^{8}$. In our case, we suspected transcutaneous entrance based on the perioperative findings (sharp end of the FB facing anteriorly). The literature review and pediatric cases are summarized in Table I. In patients with aspiration or ingestion, the diagnosis can be challenging because of the difficulty in obtaining a reliable history, as in most cases, the parents did not witness the event. In cases without a witness, patients can be diagnosed incidentally when an X-ray, taken 
Table I. Literature Review and Summary of Pediatric Cases $^{7}$ (FBs in Other Abdominal Solid Organs Were Added).

\begin{tabular}{|c|c|c|c|c|c|c|}
\hline$\overline{\text { Author(s) }}$ & Age & Sex & Diagnosis & Route & Location & Treatment \\
\hline Abel RM, et al. ${ }^{10}$ & 11 months & Male & Incidental & Stomach & Liver & Laparotomy \\
\hline Crankson SJ11 & 2 years & Male & Incidental & Unknown & Liver & No treatment \\
\hline $\begin{array}{l}\text { Le Mandat-Schultz A, } \\
\text { et al. }{ }^{12}\end{array}$ & 11 months & Male & Ingestion history & $\begin{array}{l}\text { Gastrointestinal } \\
\text { tract }\end{array}$ & Liver & Laparoscopy \\
\hline Nishimoto $Y$, et al. ${ }^{13}$ & 1 year & Male & Incidental & Transcutaneous & Liver & Laparotomy \\
\hline Azili $\mathrm{MN}$, et al. ${ }^{4}$ & 14 years & Female & $\begin{array}{l}\text { Ingestion history, } \\
\text { epigastric pain }\end{array}$ & Stomach & Liver & Laparotomy \\
\hline Inal Aslan G, et al. & 6 months & Male & Incidental & Transcutaneous & Spleen & Laparotomy \\
\hline
\end{tabular}

FB: foreign body

for another reason, shows the radiopaque FB. Many techniques can be performed in order to diagnose and locate the FB. Plain X-ray is the initial imaging for patients with suspicion of $\mathrm{FB}$ in the alimentary tract $^{6}$. Visualization of a FB in plain X-ray depends on their radiopacities. The nature of the FB can be predicted by its silhouette, size and contour. Repetitive X-ray is needed to follow the FB's progression through the alimentary tract. Sharp FBs can cause erosion, ulceration or perforation. Sharpended FBs can lead to complications, such as appendicitis, liver abscess, intussusception, or fistulas, in $35 \%$ of the patients ${ }^{1}$. They can migrate to extraluminal or extraabdominal regions, causing abscess and inflammation.

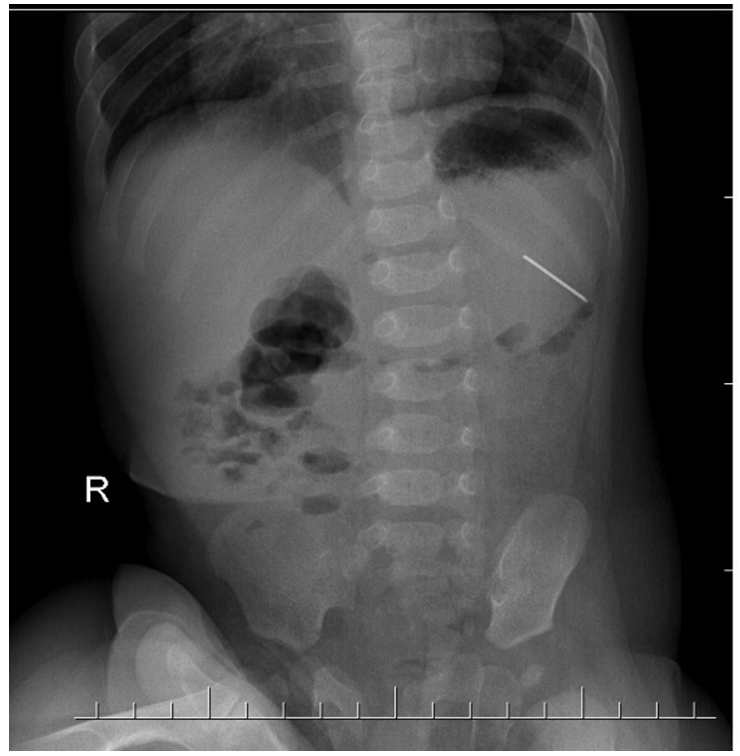

Fig. 1: Plain abdominal X-ray on admission shows the foreign body.
Ultrasound can also be used to determine if the FB is in a solid organ. Complications can be suspected with plain X-ray when the FB is immobile or causes ileus, or when free air is shown ${ }^{6}$. If a FB is stagnant, UGE can be done to locate and extract the FB. If the UGE also fails to show the $\mathrm{FB}$, as in our case, CT remains a useful technique to detect and evaluate the risks of complications ${ }^{6}$. CT also prompts scheduling of the operative intervention ${ }^{1}$.

There are two methods for the retrieval of FBs in solid organs ${ }^{7}$. In Feng et al.'s review ${ }^{7}$, 5 of 11 patients underwent laparotomy and 3 underwent laparoscopic surgery. In 3 patients, since the FB was stable without movement and not causing complications, the FB was not removed. In our case, we discussed the risks of both surgery and follow-up without treatment with the family, and surgical removal of the FB was decided in an effort to prevent complications like abscess formation. Abscess formation was advised to be treated with surgical drainage ${ }^{7}$.

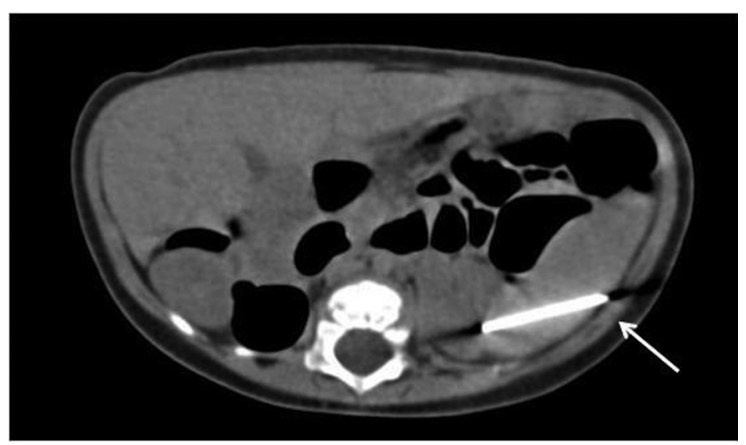

Fig. 2: Computerized tomography shows a needle, 32 $\mathrm{mm}$ in length, penetrating through the inferior pole of the splenic parenchyma (Arrow). 
In our case, there was no history of penetration. After locating the FB with CT, a detailed history obtained from the parents revealed that the patient had been hospitalized in an intensive care unit for an extended time during the neonatal period and discharged 5 months before admission to our clinic. We repeated the physical examination and found a lesion in the left subscapular area, which was likely the site of the needle's penetration. We then learned that the nurses break the plastic end of the needle to make blood sampling easier. We presume that during the patient's hospitalization in the neonatal intensive care unit, the broken needle had been inadvertently left on his bed and consequently penetrated the subscapular area and eventually punctured the spleen, passing through the paraspinal muscles. In those patients with no clear etiology, we should always consider Munchausen Syndrome by Proxy (MSBP) and child maltreatment cases $^{8}$. In our case we did not primarily think about MSBP but we assessed the family carefully. Patient did not have recurrent or permanent illnesses, did not have repeated hospitalizations or failed extensive medical tests for an undiagnosed disease ${ }^{9}$. He did not have any symptoms which could not be explained ${ }^{9}$, it was an incidental diagnosis. Parents were not overly concerned or intimate with the medical staff ${ }^{9}$. Parents did not have advanced medical knowledge ${ }^{9}$. Parents were satisfied and well adjusted for being discharged and there were no further admissions to any hospital ${ }^{9}$. Those findings were not concordant with the MSBP.

As the CT showed the FB in the splenic parenchyma, after informing the family, it was decided to operate on the patient. We were prepared for three options, total splenectomy, partial splenectomy or simply removal of the FB. We informed the parents and prepared blood for transfusion in case of bleeding after removal of the FB. During the exploration, the FB was seen to be located superficially in the spleen. It was removed with a forceps without further effort. There was no active bleeding. If the FB had been buried in the parenchyma, or in case of bleeding from the spleen, a partial or total splenectomy would have been considered.

\section{REFERENCES}

1. Yalçin S, Karnak I, Ciftci AO, et al. An unusual penetrating injury in an infant: straight-pin migration from the back to the stomach. J Pediatr Surg 2006; 41: 1332-1334.

2. Chintamani, Singhal V, Lubhana P, et al. Liver abscess secondary to a broken needle migration--a case report. BMC Surgery 2003; 3: 8.

3. Puri P, Höllwarth M, Pediatric Surgery: Diagnosis and Management. Berlin: Springer-Verlag, 2009: 205-212.

4. Azili MN, Karaman A, Karaman I. A sewing needle migrating into the liver in a child: case report and review of the literature. Pediatr Surg Int 2007; 23: 1135-1137.

5. Kadimella A. Migration of a GI foreign body into retro peritoneum without peritonitis. Indian J Surg 2011; 73: 166-167.

6.. Lee JH, Kim HC, Yang DM, et al. What is the role of plain radiography in patients with foreign bodies in the gastrointestinal tract? Clin Imaging 2012; 36: 447-454.

7. Feng QZ, Wang J, Sun H. A sewing needle in liver: a case report and review of the literature. Cases J 2009; 2: 6520 .

8. Sharif I. Munchausen syndrome by proxy. Pediatr Rev 2004; 25: 215-216.

9. Stirling J Jr; American Academy of Pediatrics Committee on Child Abuse and Neglect. Beyond Munchausen syndrome by proxy: identification and treatment of child abuse in a medical setting. Pediatrics 2007; 119: 10261030.

10. Abel RM, Fischer JE, Hendren WH. Penetration of the alimentary tract by a foreign body with migration to the liver. Arch Surg 1971; 102: 227-228.

11. Crankson SJ. Hepatic foreign body in a child. Pediatr Surg Int 1997; 12: 426-427.

12. Le Mandat-Schultz A, Bonnard A, Belarbi N, et al. Intrahepatic foreign body laparoscopic extraction. Surg Endosc 2003; 17: 1849.

13. Nishimoto Y, Suita S, Taguchi T, et al. Hepatic foreign body - a sewing needle - in a child. Asian J Surg 2003; 26: 231-233. 